\section{ACUTE TYMPANITES OCCURRING IN THE SIXTH MONTH OF PREGNANCY;}

TRGENT SYMPTOMS ; PUNCTURE OF INTESTINES ; RECOVERY. BY CHARLES WICKS, L.R.C.P., L.R.C.S.

MRs. Won Feb. 20th, suffering from quinsy and rheumatism, During attendance on these complaints I learnt that the patient was six months pregnant. All went well, recovery being uninterrupted, until the evening of Feb. 26th, when I was hurriedly summoned to see her at once, and on arrival found the patient suffering from great distension of the abdomen due to tympanites, the cause of which I was nnable to make out. The usual remedies were used, injections of assafotida \&c. having no effect. On my visit next morning I found the patient worse, and the symptoms very much exaggerated. She complained of great discomfort generally, although no actual pain. The breathing was very short and quick, and the pulse small, beating about 125 per minute; the temperature was $100^{\circ}$. Other remedies were then tried, and on the evening of the same day I was again sent for urgently. On arrival $I$ found the patient cyanotic, the pulse 130 , and labour commenced, evidently due to the irritation of the distended bowel on the uterus. Regarding the case as very critical, and seeing that all the remedies used had entirely failed to give any relief, I asked Professor Oliver to see her with me in consultation. Having talked the matter over with him, and, having enumerated the various methods that had been employed to give relief, we agreed that the only and best chance left for her was to puncture the abdomen, and thus relieve not only the general discomfort, but also probably stop the progress of labour. We accordingly punctured the abdomen in four places with a medium-sized trocar. This immediately relieved the patient, gas rushing freely from the instrument. In a few minutes she was able to express herself as feeling much better. Her breathing rapidly improved, cyanosis disappeared, and the pulse fell from 130 to 110 . A dose of morphia was prescribed, and we left her feeling, as she said, very comfortable. On visiting her two hours later, I was pleased to find that the tympanitic distension had very greatly disappeared, but disappointed, on the other hand, that labour was progressing. The pulse was 105 , and the temperature $100^{\circ}$. Labour was completed one hour and a half later, the patient having endured it well. One hour after confinement the pulse was 100 , and the patient felt inclined to sleep, lying in the recumbent position without any inconvenience, a position hitherto unattainable. On my visit next morning I was pleased to find that the abdominal symptoms had entirely disappeared, and to learn that the patient had had a very comfortable night, had passed some flatus by the bowel, and felt wonderfully well, the pulse being 80 and the temperature normal. The following morning a violent attack of diarrhoea set in, which weakened her considerably ; this, however, was soon controlled by a mixture of dilute sulphuric acid with opium. A few days afterwards I ordered a mixture containing belladonna and nux vomica; and after a period of nine days she was able to be out of bed, the pulse and temperature being normal and the bowels acting regularly.

Remarks by Professor OLIVER.-Had it not been for the timely interference by acupuncture in this case, one cannot but admit that it would soon have ended fatally. The extremely distended abdomen had so completely fixed the diaphragm as to make respiration difficult and the emptying of the heart all but an impossibility, and it was absolutely necessary, with labour in progress, that relief should be sudden; and effective acupuncture gave this.

Newcastle-on-Tyne.

DeATH FROM THE BITE OF A CAT.-A young woman named Elizabeth $J_{\text {ones }}$ died in Liverpool last week from hydrophobia, caused through a bite from a favourite cat, which about two months ago became ill and bit the dereased while she was tending it. The cat, it appears, had heen taken over to Cavan, Ireland, some time prerionsly, and was there bitten by a dog, although the dogs in the district were supposed to be under control on account of the prevalence of rabies.

\section{g. attirux OF}

\section{HOSPITAL PRACTICE, BRITISH AND FOREIGN.}

Nulla autem est alia pro certo noscendi via, nisi quamplurimas et morborum et dissectionum historias, tum aliorum tum proprias collectas borum et dissectionum historias, tum aliorum tum proprias collectas
habere, et inter se comparare.-MoRGAGNI De Sed. et Caus. Mort., habere, et inter s
lib. iv. Procmium.

\section{EVELINA HOSPITAL FOR CHILDREN.}

ACUTE NECROSIS OF THE POSTERIOR ARCH OF THE ATLAS, WITH ABSCESS ; ESCAPE OF CEREBRO-SPINAL YLLUID; MENINGITIS AND SEPTICAMIA; NECROPSY.

(Under the care of Mr. R. Clement Lucas.)

ACUTE NECRosis of any of the vertebræ is of rare occurrence, and has seldom been met with in the cervical region of the spine; the following case is therefore of considerable importance, and is worthy of careful study. It is evident that the history of the case is very much that met with in a large majority of the children applying for relief in an out-patient department, suffering from acute glandular abscess from the irritation of the scalp due to pediculi capitis, and the local condition was a similar one, excepting that the abscess was in the middle line. In this instance such a source of irritation was present, and for a time was regarded as a sufficient cause for the condition, the pneumonia which developed accounting for the unusual amount of constitutional disturbance before the onset of the pyæmic state. On the appearance of the cerebro-spinal fluid four days after incision of the abscess, there could be no longer any doubt as to the extent of the disease or of the gravity of the prognosis. When similar acute disease has developed in other parts of the spine-in the lumbar region, for instance-marked dilatation of the superficial veins has been observed, and the abscess has attained considerable size before recognition. For the notes of the case we are indebted to Mr. G. Herbert Pennell, house-surgeon.

C. $\mathrm{R}-$, aged seven, was adnitted on Jan. 3Ist, 1889. The mother took him to the hospital on account of a painful swelling at the nape of the neck, and gave the following history. The boy had been ailing about a fortnight, complaining chiefly of headache, and four days before admission a swelling was noticed in the nape of the neck, which had grown very painful. The family history was unimportant, and beyond the illnesses of childhood the boy had up to the present time enjoyed good health.

On admission there was found at the junction of the scalp with the skin of the neck, directly in the median line behind, a fluctuating swelling of about the size of a walnut, around which the skin was brawny and inflamed. The hair was full of pediculi and nits, but there were no enlarged glands to be felt. The patient had a harassing cough, a flushed face, and a temperature of $103.5^{\circ}$. No marked physical signs were found in the lungs, and the urine was normal. The scalp was treated with Stavesacre ointment, and a linseedmeal poultice applied to the abscess on the nape of the neck. By the next morning (Feb. 1st) his temperature had fallen to $100.5^{\circ}$, and though it rose to $104^{\circ}$ in the evening, it had fallen to $99^{\circ}$ by the morning of Feb. 2nd. Meanwhile the poultices had much relieved the pain in the neck. The patient seemed fairly confortable, was sitting up in bed, and taking food well.

Feb. 3rd.--Improvement maintained. The temperature has not exceeded $101^{\circ}$.

th. - In the evening his temperature ran up to $104^{\circ}$, but his neck gave him less pain. On examining his chest signs of consolidation were found round the right base. An ice poultice was applied and a simple expectorant ordered.

5th.- Temperature normal in the morning, running up to $103^{\circ}$ in the evening, but falling again to $100^{\circ}$ on the 6 th.

7 th.-Abscess in the neck opened and about two ounces of apparently laudable pus evacuated. The ice poultice to his side was discontinued.

8th. - Wound dressed. Temperature normal in the fore noon, and only traces of the pulmonary consolidation found 